\title{
Characteristics of Reproductive Tracts of Repeat Breeders in Cattle
}

${ }^{1}$ Kubkomawa H. I., ${ }^{2}$ Nafarnda, W. D. and ${ }^{3}$ Neils, J. S.

1. Department of Animal Health and Production, Federal Polytechnic, PMB 35 Mubi,

Adamawa State Nigeria.

Department of Animal Anatomy University of Abuja. F.C.T, Nigeria

3.Department of Animal Production, Adamawa State University Mubi

Corresponding Author : Kubkomawa H. I. Department of Animal Health and

Production, Federal Polytechnic PMB 35 Mubi, Adamawa State, Nigeria.

\section{Abstract}

Email-kubkomawa@yahoo.Com,07066996221

The study observed the characteristics and assessed abnormalities in reproductive tracts of repeat breeders in cattle. Fourty (40) herds were sampled during the study and fifty seven (57) repeat breeders were identified. The animals had normal reproductive tracts with good body condition scores (BCS) ranging from 2.5-4.5. There was no correlation between the ages and the body condition scores of the repeat breeders $(r=-0.4576$. Higher number of repeat breeders were found within the ages of $3-6$. Variation within the ages of the repeat breeders were not significantly associated. Physical and behavioral characteristics observed were: crystal clear eyes; appearing more like a castrated bull; physically strong; active; vibrant; alert; stubborn; wild; temperamental; aggressive and difficult to handle; very sensitive to their environment and have a quick idea of the presence of a stranger which they show by having their ears in erect disposition signaling a sign of insecurity and danger. They always appear as superior animals in the herds; and could even be used as draught or pack animals with a very good output. They could yield better meat compared to none repeat breeders in the herds. Thus, most repeat breeders are not sterile, have normal oestrus cycle every 18-24 days but rather suffer from lowered fertility resulting to huge economic waste due to more services; reduced milk yield; wide calving interval and culling rate. It was concluded that repeat breeders suffer from lowered fertility which results into reduced milkyield, wide calving interval and culling rate.

Key words: characteristics, reproductive tracts, repeat breeders, cattle, body conformation

\section{Introduction}

Repeat breeder cows and heifers exhibit normal signs of oestrus every 18 to 24 days but require more than three services to become pregnant (Hafez and Hafez, 2000, NADIS, 2002, Todd, 2008). Ten to $15 \%$ of cows and heifers that fail to conceive on time can be classified as repeat breeders (Todd, 2008). There are only few studies that analyzed risk factors using field data (Bartlett et al., 1986, Lafi et al., 1992 and Brooks, 1998). These studies have found factors such as season, herd size, age and nutrition to influence the incidence of repeat breeding syndrome. Some of the earlier studies, have the weaknesses that the data were restricted to a limited number of herds and animals and that the repeat breeders were not strictly identified according to the definition "absence of detectable abnormalities". In addition, most of the studies identifying fertility problems are not always related to a specific clinical sign (Katagiri and Takahashi, 2004; Givens, 2006).

There is no reported literature on the characteristics and reproductive tracts of 
repeat breeders in cattle in Nigeria. The study therefore aimed at studying the characteristics and reproductive tracts of repeat breeders in some cattle herds of Adamawa state, Nigeria.

\section{Materials and Methods}

Forty (40) White Fulani (Bunaji) herds with repeat breeders were surveyed in four selected Local Government Areas (Girei, Yola North, Yola South and Fufore) of Adamawa State between January and April, 2009. Herds with more than 15 female animals were included in this study. A cow or heifer was considered a repeat breeder if she had at least three services and no subsequent calving or more than three services irrespective of subsequent calving . Cow or heifer treated at least once for any chronic reproductive disease such as cystic ovaries, an oestrus, suboestrus, endometritis and pyometra was not considered repeat breeder. Data on the physical and behavioral characteristics of the repeat breeders were obtained on herd basis by close observation, examination of the animals, oral interview of the herdsmen and the use of farm records where available. The reproductive tracts of the repeat breeders were assessed through rectal palpation. Data on the ages were obtained using dentition as described by Sastry and Thomas (1980). Body condition score (BCS) of the animals were taken as described by Todd (2008) using the six grades 05 . While parity and milk yield were obtained through the oral interview of the herdsmen and the herds owners. The management system adopted by many herds were mostly extensive with few operating semi intensive. The breeding systems used were both natural mating and artificial insemination (AI). Data generated were subjected to descriptive statistics, chi- square and correlation analysis to evaluate the association and the relationship between the ages and BCS of the repeat breeders.

\section{Results and Discussion}

Fifty seven (57) repeat breeders identified from forty (40) herds were examined and were found to have no abnormality of reproductive tracts and were cycling normal with top $\mathrm{BCS}$ ranging from 2.5-4.5 as shown in

Table 1.Grouping Of Repeat Breeders

Based On Their Ages, PI, Parity And MY

\begin{tabular}{llll}
\hline $\begin{array}{l}\text { Age } \\
\text { group }\end{array}$ & PI & Parity & MY \\
\hline $3(13)$ & $2(13)$ & 0 & 0 \\
$4(20)$ & $3(20)$ & 0 & 0 \\
$5(16)$ & $4(16)$ & 0 & 0 \\
& & & $2(1)$, \\
$6(8)$ & $4(8)$ & 3 & $2(1)$
\end{tabular}

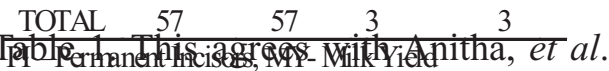
(2005) and Mohammad and Seyed (2007), who reported that the repeat breeder cows have the best BCS after bulls. There was no correlation between the ages and the body condition scores of the repeat breeders $(r=-0.4576)$ as presented on Table 2. The higher the grade and the younger the animals the better the body condition score.Most of the animals fall within 3- 6 years old and that shows they were in their prime reproductive lives. Higher number of repeat breeders were found within the ages of 4 followed by 5, 3 and 6 respectively. Variation within the ages of the repeat breeders were not significantly associated. It also implies that all ages within the repeat breeders are feasible. 


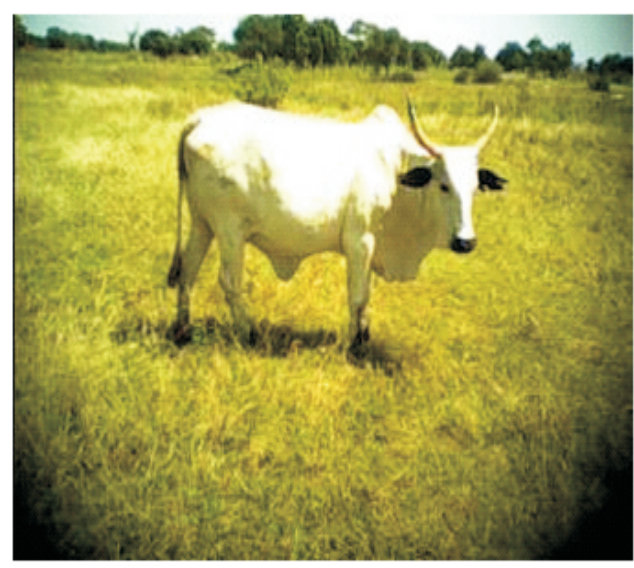

Figure 1. Typical repeat breeder having good body conformation with top BCS

Most of the animals fall within 3- 6 years old and that shows they were in their prime reproductive lives. Higher number of repeat breeders were found within the ages of 4 followed by 5,3 and 6 respectively. Variation within the ages of the repeat breeders were not significantly associated. It also implies that all ages within the repeat breeders are feasible.

Seven animals were found pregnant, 10 cyclic, 40 non- cyclic. Out of 57 repeat breeders, the 3 animals that were found to have calved once gave a total milk yield of 4 litres as presented in Table 1 . This agrees with the

findings of Erb and Martin (1980) and NADIS (2004) who reported that $30 \%$ of lactations are affected by infertility and reproductive disorders, and $3-6 \%$

\begin{tabular}{|c|c|c|c|c|c|c|}
\hline \multirow{2}{*}{ AGE } & \multicolumn{6}{|c|}{$\mathrm{BCS}$} \\
\hline & & & & & & \\
\hline 3 & 0 & 4 & 4 & 3 & 2 & 13 \\
\hline 4 & 0 & 5 & 8 & 4 & 3 & 20 \\
\hline 5 & 0 & 2 & 3 & 9 & 2 & 16 \\
\hline 6 & 1 & 2 & 3 & 2 & 0 & 7 \\
\hline TOTAL & 1 & 13 & 18 & 18 & 7 & 57 \\
\hline
\end{tabular}

BCS - Body Condition Score of the herd is culled annually in developed countries for these reasons which constitute an economic threat to cattle industry.

Out of 120 herd workers interviewed, $90 \%$ of them and physical examination revealed that repeat breeders have physical and behavioral characteristics as: crystal clear eyes; physically appearing more like castrated bulls; active; alert; wild; and difficult to handle; very sensitive to their environment and have a very quick idea of the presence of a stranger which they show by having their ears being in erect disposition signaling a sign of insecurity. They always appear as superior animals in the herds as shown in Figures 1and 2. They are strong and could be used as draft or pack animals with a very good output. They could even yield better meat compared to none repeat breeder female animals in the herds.

\section{Conclusion}

In conclusion, most repeat breeders are not sterile, they have normal reproductive tracts with top BCS. They also have normal oestrus cycle but rather suffer from lowered fertility, resulting to huge economic due more services; reduced milk yield; wide calving interval and culling rate.

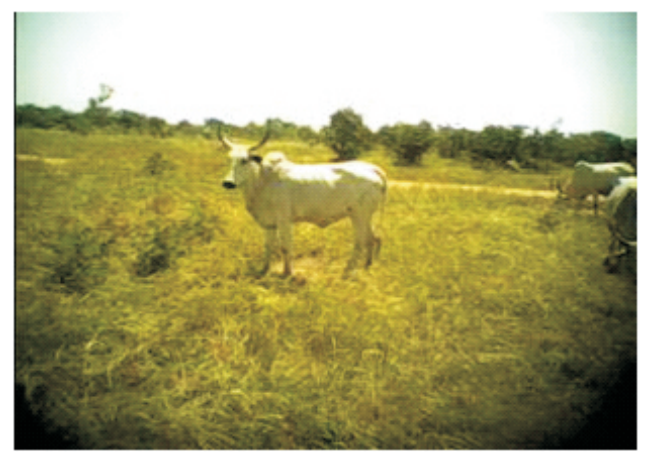

Figure 2.Typical repeat breeder Leading other animal 


\section{Recommendations}

If only the repeat breeders and other animals with reproductive problems can be identified, there could be treatment and prevention measures taken. If regular veterinary fertility visits are not used then cows that have had three services and are not pregnant should be checked before serving again. To prevent repeat breeding syndrome in cows; ensure that cows served at the correct time. These means that all staff should know the signs of heat. Milk progesterone testing is also useful; cows in a true heat will have very low progesterone. Farmers should also ensure insemination techniques are as good as possible. This is particularly important, if A.I. is used, do not serve cows previously diagnosed as pregnant without doing a cow side progesterone test to confirm it has a low progesterone and is not pregnant. Ensure that farmers comply to a resynchronization programmes.

\section{References}

Anitha, A., Rao, K.S., Ramana, J.V. and Reddy, P.V.V.S.(2005): Influence of body conditions score on service period and incidence of clinical mastitis in crossbred cows. Indian Veterinary Journal.82:3:283285

Bartlett, P. C., J. H. Kirk and E. C. Mather, (1986). Repeated insemination in Michigan Holstein Friesian cattle: Incidence, descriptive epidemiology and estimated economic impact. Theriogenology, 26: 309322.

Brooks, G. (1998). Fertility of repeat breeder cows in subsequent lactations Veterinary Record 143: 615-616

Erb H N and Martin S W. (1980). Interrelationships between production and reproduction diseases in Holstein cows. Journal of Dairy Science 63: 1911-1917.

Givens, M.D.(2006). A clinical, evidence-based approach to infectious causes of infertility in $\mathrm{b}$ e e f c a t t le. Theriogenology.66:3:648-654.

Hafez, B. and Hafez, E.S.E. (2000): Reproduction in farm animals Kiawah Island South Carolina USA, 7th Ed. 269-402

Katagiri, S. and Takahashi, Y.(2004). Changes in EGF concentrations during estrous cycle in bovine endometrium and their alterations in repeat breeder cows. Theriogenology. 62:(1-2):103-112.

Lafi, S.Q, Kaneene, J.B, Black, J.R, and Lloyd, J.W. (1992): Epidemiological and economic study of the repeat breeder syndrome in Michigan dairy cattle. II Economic modeling. Preventive veterinary medicine. 14:99 114.

Mohammad, R. A. and Seyed, A. D. (2007): Evaluation of the treatment of repeat breeder dairy cows with uterine lavage plus PGF2 2 , with and without cephapirin. Turk. J. Vet. Sci:31:2.125-129

NADIS (2002): National Animal Disease Information Service. A Network Of 40 Veterinary Practices And 6 Veterinary Colleges Monitoring Diseases In Cattle, Sheep And Pigs In The U.K, Including BPEX, EBLEX, HCC, QMS, Elanco Animal Health, MLC And Merial.

NADIS (2004): National Animal Disease Information Service. A Network Of 40 Veterinary Practices And 6 Veterinary Colleges Monitoring Diseases In Cattle, Sheep And Pigs In The U.K, 
Including BPEX, EBLEX, HCC, QMS, Elanco Animal Health, MLC And Merial.

Sastry, S. R. and Thomas, C. K.(1980): Dentition in farm animal management. Pp 39 45. VIKAS Publishing house PVT ltd India.

Todd, R. B. (2008): Getting those repeat breeders bred. Western Dairy News. Agrilife Extention and Research Texas A and M University 8: 7 